\title{
The effect of different colored light emitting diode illumination on egg laying performance, egg qualities, blood hormone levels and behavior patterns in Brown Tsaiya duck
}

\author{
Chin-Hui Su ${ }^{1,2}$, Chih-Hsiang Cheng ${ }^{2}$, Jung-Hsin Lin ${ }^{2}$, Hsiu-Chou Liư ${ }^{2}$, Yen-Ting Yu ${ }^{1}$, \\ Chai-Ching Lin ${ }^{1}$, and Wei-Jung Chen ${ }^{1, *}$
}

\begin{abstract}
* Corresponding Author: Wei-Jung Chen Tel: +886-3-931-7623, Fax: +886-3-935-4152

E-mail:wjchen@niu.edu.tw
\end{abstract}

${ }^{1}$ Department of Biotechnology and Animal Science, National Ilan University, Yilan, Yilan 260007, Taiwan

${ }^{2}$ Ilan Branch, Livestock Research Institute, Wujie Township, Yilan 268020, Taiwan

ORCID

Chin-Hui Su

https://orcid.org/0000-0001-5084-3004

Chih-Hsiang Cheng

https://orcid.org/0000-0002-3785-9420

Jung-Hsin Lin

https://orcid.org/0000-0002-3015-8269

Hsiu-Chou Liu

https://orcid.org/0000-0002-9135-0609

Yen-Ting Yu

https://orcid.org/0000-0001-9514-1559

Chai-Ching Lin

https://orcid.org/0000-0002-8092-1920

Wei-Jung Chen

https://orcid.org/0000-0001-7489-1019

Submitted Sept 17, 2020; Revised Dec 8, 2020; Accepted Jan 11, 2021
Objective: The objective of this experiment was to investigate the effects of different colors produced by light emitting diode (LED) on Brown Tsaiya ducks.

Methods: A total of 144 female Brown Tsaiya ducks were randomly allocated into three individual cage rearing chambers with different LED illumination colors as treatments. Three different treatments were: i) white color, ii) blue color, and iii) red color. The experiment periods were from ducks 21 to 49 weeks of age, determined traits included i) egg laying performance, ii) feed intake, iii) egg shell breaking strength, iv) egg shell thickness, v) egg Haugh unit, vi) egg weight, vii) serum Estradiol and Progesterone concentration, and viii) behavior pattern.

Results: The results indicated that when compared with white and blue color, red color could stimulate ducks sexual maturation and raised the egg laying performance. The red light group was also observed to have the highest feed intake among three treatments. The blue treatment had the lowest egg shell breaking strength and the highest egg weight among three treatments, nevertheless, no significant difference was observed among three treatments on egg shell thickness and egg Haugh unit. The red light group had higher serum estradiol concentration than the white and blue groups, but no significant difference among treatments on the serum Progesterone concentration was found. The results of behavior pattern indicated that red light group showed more feeding and less resting behavior compared to the blue light group.

Conclusion: We found a potential of applying red light illumination in the indoor laying duck raising system with positive results on egg laying performance and acceptable egg weight, equivalent egg qualities compared to white and blue light.

Keywords: Brown Tsaiya Duck; Illumination; Light Emitting Diode

\section{INTRODUCTION}

Environmental manipulation is an effective means to improve poultry production and welfare $[1,2]$. Among those environmental factors, light plays a vital role in affecting chicken production [3]. Light has five basic characteristics: source, intensity, duration, uniformity, and wavelength (light color) [4]. Research on poultry lighting dates back to the early 1930s. Since then, extensive research has led to a broad understanding of lighting effects on poultry [5]. Recently, more energy-efficient, durable, affordable, and dimmable light-emitting diode (LED) lights are increasingly finding applications in poultry production. Due to light is a crucial environmental factor that affects bird behavior, development, production performance, health, and well-being [6,7], the emerging LED lighting in poultry housing has getting increasing attention from both scientific and industrial communities. 
Because of having specific adaptations, like a fourth type of retinal cone and eye lenses that are clear to short-wave light $[8,9]$, poultry can see a wider range of the light spectrum than humans. The estimation of their visual range differs somewhat between studies, starting around 350 to $380 \mathrm{~nm}$ and ending at 760 to $780 \mathrm{~nm}$ [9]. This means that poultry's visual spectrum includes UV-A light, but likely just excludes infrared light. This wide spectrum was not only determined by assessing the electrophysiological capacity of the cone cells but also confirmed using behavior tests [8].

It is found that laying hens were healthier and showed better laying performance with $25 \%$ less cholesterol in the egg when they were given whole spectrum illumination [10], another reference compared the effect of fluorescent tube and LED on laying hens found that no significant influence on laying performance and $7 \%$ of feed intake and $17 \%$ of energy cost was reduced in LED treatment [11]. Nonetheless, some review article concluded that there was no influence on laying performance when given white and green illumination stimulation on laying hens [12].

Tai and Hsieh [13] compared the effects of five different wavelengths LED illumination including blue $(473 \mathrm{~nm})$, green $(530 \mathrm{~nm})$, red $(625 \mathrm{~nm})$, orange $(603 \mathrm{~nm})$, and warm white $(5500 \mathrm{~K})$ on broiler breeding eggs' hatchability, the results indicated that eggs exposure blue, red and warm white illumination showed better hatchability, however, green light increase the deformity rate.

Raising ducks on the floor with litter and water pond in the field is the conventional method to breed ducks in Taiwan. However, with the level of invasion of avian influenza getting severer, it is a trend to raise ducks in the duck house. Because ducks accept natural illumination when they are bred by conventional methods, an artificial illumination source has to be a supplement in the duck house that ducks can receive enough lighting stimulation. Most of the illumination used in Taiwan in animal husbandry houses is still fluorescent tubes and high-pressure sodium lamp. They are more inefficient compare to the LED on lifetime and energy cost. The advantages of LEDs are high energy change efficiency, small volume, long lifetime, fixed wavelength, and low heat. LED illumination has high energy savings potential. There is also no mercury in LED lamps, contributing less to environmental pollution. Some researches focused on the LED illumination effects on poultry. However, only a few references tested this effect on waterfowl. Therefore, this experiment investigates the effects of different colors produced by LEDs on Brown Tsaiya ducks. This study sought to find the best illumination pattern for indoor laying ducks.

\section{MATERIALS AND METHODS}

\section{Animal care}

The experiment was conducted between February and September 2015 and carried out at the Ilan Branch, Livestock Research Institute, Council of Agriculture, Taiwan (244ㅇ' $22^{\prime \prime}$ $\mathrm{N}$ and $121^{\circ} 49^{\prime} 55^{\prime \prime} \mathrm{E}$, and altitude of $7 \mathrm{~m}$ above sea level). The experimental procedure was approved by the Institutional Animal Care and Use Committee at Ilan Branch, Livestock Research Institute, Council of Agriculture (case number: 104 - 007).

\section{Experimental light}

The experimental LED (Sanan Optoelectronics Co. Ltd., Xiamen, China) illumination was placed at the ducks' head level. The average light intensity was 60 lux based on blue light. White and red lights were adjusted following Benoit [14] as similar light stimulation. The daily lighting pattern was 16 $\mathrm{L}: 8 \mathrm{D}$ and the white light color temperature was $6000 \mathrm{~K}$. The peak wavelengths for blue and red light were 460 and 630 $\mathrm{nm}$ (wavelengths distribution were shown in Figure 1, determined by Integrating Sphere, Zvision, Beijing, China), respectively. Ducks were given a $16 \mathrm{~L}: 8 \mathrm{D}$ lighting program with the illumination time from 5 am to $9 \mathrm{pm}$. The dark time was from $9 \mathrm{pm}$ to $5 \mathrm{am}$.

\section{Experimental animal}

One hundred forty-four self-bred female brown Tsaiya ducks were used in this experiment. All ducks were reared in a breeding house and fed starter diets until 4 weeks of age. Thereafter, ducks were moved into a semi-open duck house and fed a grower diet during the growing period until 18 weeks of age. At 18 weeks of age, the ducks were randomly allocated into three individual opaque chambers with layer diets given at the same time. After three weeks of layer diet, cage feeding and experimental illumination were adapted. The experiment was started at 21 weeks of age and lasted to 49 weeks of age.

\section{Experimental diet}

Ducks were provided with ad libitum commercial duck starter diet from hatching to 8 weeks of age. Grower and layer diets were provided between 8 to 18 weeks of age and after 18 weeks, respectively. Different diet compositions and calculated nutrition levels are shown in Table 1. Food and water were given ad libitum during this experiment.

\section{Experimental facility}

Three identical opaque chambers, each measuring $570 \times 330 \times$ $235 \mathrm{~cm}(\mathrm{~L} \times \mathrm{W} \times \mathrm{H})$, were used in the laying phase. Each chamber contained 48 cages ( 12 cages per tier $\times 4$ tiers), with each measuring $40 \times 30 \times 45 \mathrm{~cm}(\mathrm{D} \times \mathrm{W} \times \mathrm{H})$ with a space allowance of $1,200 \mathrm{~cm}^{2} /$ duck. The feeder was hung outside the front side of the cage. A one nipple drinker was set on the backside. 


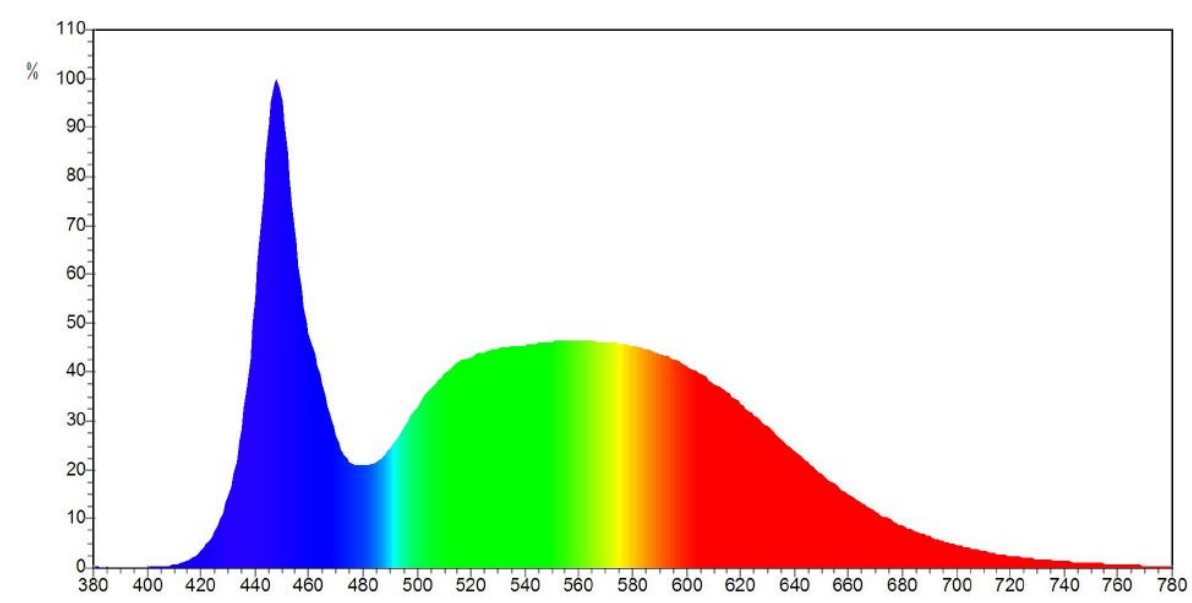

Wavelength/nm

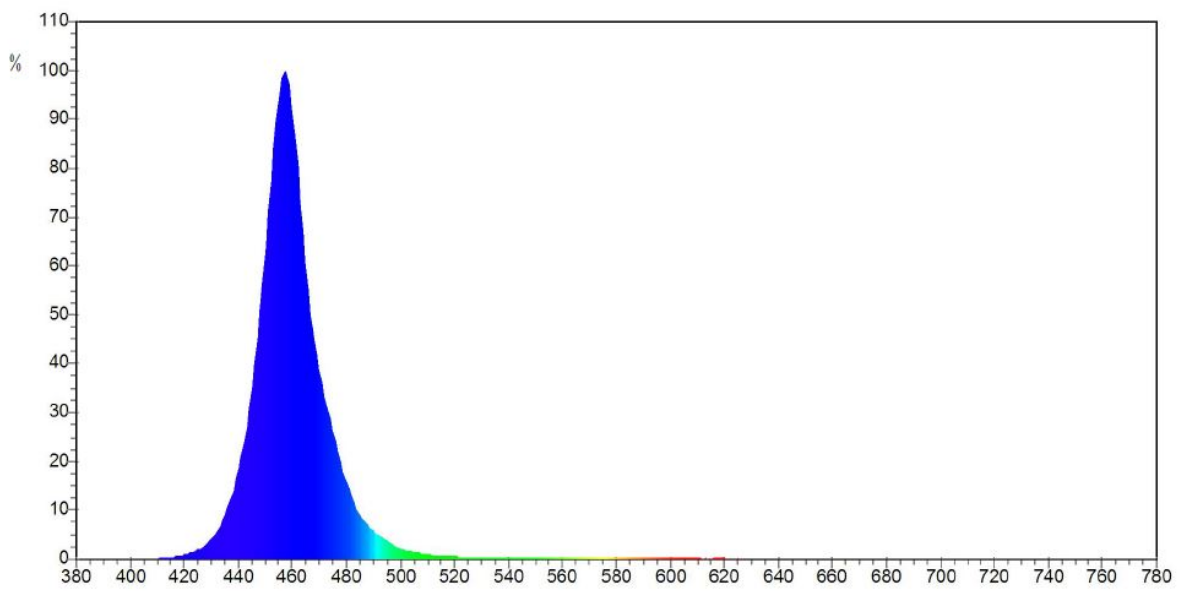

Wavelength/nm

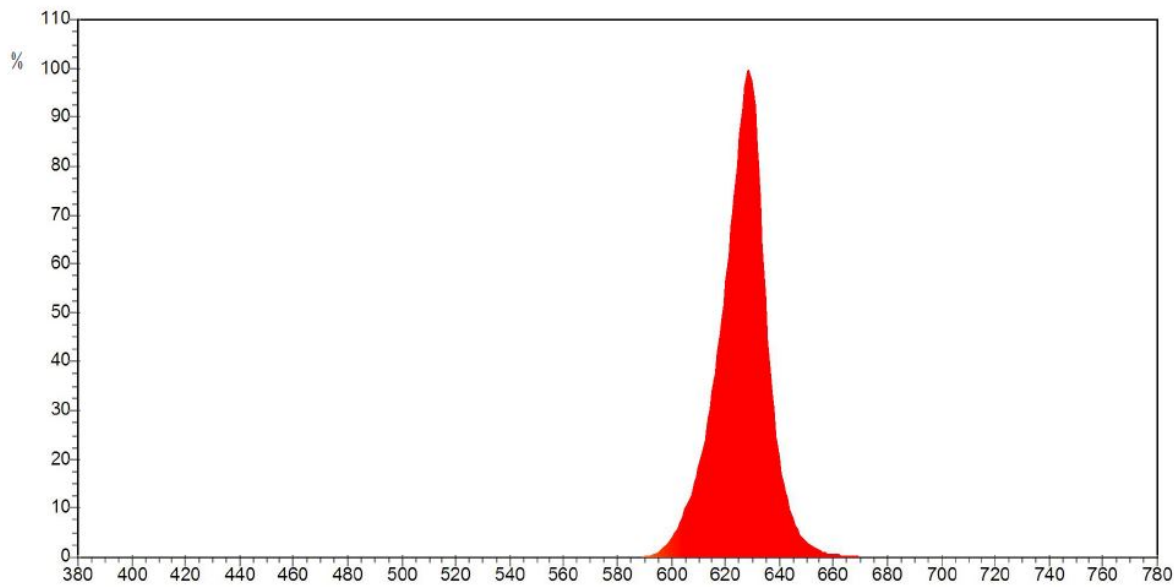

Wavelength/nm

Figure 1. The wave length distribution of the white, blue and red light emitting diode (LED) lamp in the experiment. The peak wavelengths for blue and red light were 630 and $460 \mathrm{~nm}$, determined by Integrating Sphere, Zvision, Beijing, China. 
Table 1. Diet ingredients and composition in the rearing period (0 to 8 weeks of age), growing period (8 to 18 weeks of age) and laying period (after 18 weeks of age)

\begin{tabular}{lccc}
\hline Items & $\begin{array}{c}\text { Rearing } \\
\text { diet }\end{array}$ & $\begin{array}{c}\text { Growing } \\
\text { diet }\end{array}$ & $\begin{array}{c}\text { Layer } \\
\text { diet }\end{array}$ \\
\hline Ingredients & & & \\
$\quad$ Yellow corn & 55.54 & 51.94 & 49.93 \\
Soybean meal (44\%) & 25.30 & 10.00 & 27.00 \\
Wheat flour middling's & 10.30 & 20.00 & - \\
Wheat bran & - & 10.00 & 6.50 \\
Fish meal & 2.00 & - & 3.30 \\
Yeast powder & 3.00 & 2.00 & 2.00 \\
Rice hull powder & - & 2.40 & - \\
Soybean oil & 1.10 & - & 2.50 \\
Limestone & 1.10 & 1.60 & 6.60 \\
Di-calcium phosphate & 1.10 & 1.50 & 1.50 \\
Salt, iodized & 0.30 & 0.30 & 0.40 \\
Choline chloride (50\%) & 0.08 & 0.08 & 0.08 \\
Lysine-HCl & - & - & 0.01 \\
DL-methionine & 0.05 & 0.05 & 0.05 \\
Vitamin premix & 0.03 & 0.03 & 0.03 \\
Mineral premix & 0.10 & 0.10 & 0.10 \\
Calculated nutritional value & & & \\
ME (kcal/kg) & 2,900 & 2,660 & 2,700 \\
Crude protein (\%) & 19.5 & 13.5 & 20.0 \\
Calcium (\%) & 0.81 & 0.94 & 3.05 \\
Available phosphorus (\%) & 0.36 & 0.44 & 0.44 \\
Methionine (\%) & 0.38 & 0.27 & 0.39 \\
Lysine (\%) & 1.05 & 0.60 & 1.11 \\
\hline ME metabolizale & & &
\end{tabular}

ME, metabolizable energy.

The thermal environment conditions in the chambers were controlled using two diameter $40.64 \mathrm{~cm}$ fans in the front and backside of the chamber, respectively.

\section{Experimental method}

Egg laying performance: The number of eggs laid was recorded daily for egg production calculation. Feed intake was collected by calculating the sum of residual feed in 4 tiers as 4 repeats on 3 consecutive days during the week.

Egg quality: All of the eggs were collected for egg quality determination, including egg weight, egg shell breaking strength, egg shell thickness, egg albumen height, Haugh unit on three consecutive days biweekly and tested within $24 \mathrm{~h}$ after collection. The experimental procedures are described below:

i) Egg weight: an electronic scale (FAY-06, Nagata Inc., Tainan, Taiwan) was used for egg weight determination.

ii) Egg shell breaking strength: put the point side up, then crack the eggs with an egg shell break instrument (HT-9635A, Hung Ta Inc., Taoyuan, Taiwan) and record the maximum breaking force.

iii) Egg shell thickness: three different parts, including the point side, blunt side and the central portion of the eggs were collected from each egg for egg shell thickness determination (FN595, FHK Inc., Tokyo, Japan). The recorded egg shell thickness values were the average of three different measurements.

iv) Egg albumen height: egg albumen height was measured using a tester (FHK Egg Quality Gauge, FHK Inc., Japan)

Blood hormone levels: Sixteen fixed ducks in the middle area of each treatment were chosen for duck blood Estradiol and Progesterone concentration, analyzed biweekly after 22 weeks of age. Between 2 and $3 \mathrm{~mL}$ of blood were collected using syringes from the wing vein of each duck. The blood was injected into a plasma separation gel and lithium heparin vacutainer (BD 367871, BD, Franklin Lakes, NJ, USA) and temporarily stored on an ice bath. After all samples were collected, the vacutainers were spun down in an IEC MULTIRF220v centrifuge for $15 \mathrm{~min}$ at 3,000 rpm to separate the cells from the plasma. The plasma was poured into $2 \mathrm{~mL}$ microcentrifuge tubes and stored at $-18^{\circ} \mathrm{C}$ until further analysis. Plasma Estradiol and progesterone concentration determination were entrusted to a commercial analytical laboratory (Health Medical Laboratory) using commercially available kits (06656021 190; 07092539 190, Roche, Basel, Switzerland) according to the manufacturer's instructions.

Animal behavior observation: From 21 weeks of age, every two weeks, ducks were recorded using a digital video recorder (HDR CX-240, Sony, Tokyo, Japan) positioned in the front part of each chamber. Video recording was used four days in a week for behavior observation in each treatment until 49 weeks of age. Five ducks were observed for 8 hours on an observation day with 4 observation days in a week. The first observation time was 30 minutes after recording begin to avoid worker disruption. At each hour, ducks were monitored for 15 seconds for behavior determination. Behavior observation during the experiment was visually recorded and analyzed by one observer to minimize behavior definition variation induced by different observers. Duck behavior definition was followed and slightly modified from Lee [15]. Duck behaviors were divided into three main categories: feeding (including feeding and drinking), activities (including preening, frolicking and wagging) and resting (including standing, crouching and sleeping). The behavior definitions are described in Table 2.

\section{Statistical analysis}

Statistical analyses were performed using SAS enterprise (SAS enterprise guide 7.1, SAS institute, Inc., Cary, NC, USA). All variables were analyzed using the general linear model procedure in a completely random design with different colored LEDs as the main effects. The differences among treatments were evaluated using Tukey's honestly significant difference. Probability values of $<0.05$ were taken to indicate significance. Duck behavior patterns were subjected into three categories 
Table 2. The definition of cage rearing Brown Tsaiya ducks behaviors

\begin{tabular}{ll}
\hline Behavior & \multicolumn{1}{c}{ Definition } \\
\hline Feeding & Pecking feed \\
Drinking & Pecking water supplier \\
Preening & Touching the feather via beak or scratching via claw \\
Frolicking & Shaking head rhythmically or pecking the cage, nearby ducks' body and head genetically, or head out of the cage \\
Wagging & Standing and wagging tail rapidly without other frolicking behavior \\
Standing & Standing with two feet, eyes looking at forward or around \\
Crouching & Duck's breast and abdomen touching the cage bottom, feet crouched, eyes looking at forward or around \\
Sleeping & Leaning head on or inside the wings, duck stopped without moving \\
\hline
\end{tabular}

including feeding, activities and resting. These three categories were analyzed with the categorical data analysis (CATMOD) procedure to compare the difference between the three treatments.

\section{RESULTS}

\section{Egg laying performance}

The egg laying performance results for all treatments are shown in Table 3. The results indicated that the red LED treatment had significantly higher egg laying performance for the testing period of 27 to $32(84 \% \pm 2 \%), 39$ to $44(71 \% \pm 4 \%)$ weeks of age and the whole testing period $(74 \% \pm 9 \%)(\mathrm{p}<0.05)$. There were no significant differences between the white and blue LED treatments for the most part in the testing period except for the 39 to 44 weeks of age period.

\section{Feed intake}

The feed intake results represent higher egg laying performance for the red LED treatment (Table 4). In the 21 to 25 ( $157 \pm 15 \mathrm{~g}), 27$ to 31 (151 $\pm 6 \mathrm{~g}), 45$ to 49 (162 $\pm 8 \mathrm{~g})$ weeks of age and whole testing period $(153 \pm 12 \mathrm{~g})$. The red light group had the highest feed intake of all groups. This may combine with their better egg laying performance. There was no significant difference between the white and blue LED treatments throughout the whole experimental period.

Table 3. The egg laying performance of Brown Tsaiya ducks in different treatment groups

\begin{tabular}{|c|c|c|c|}
\hline Weeks of age & White LED & Blue LED & Red LED \\
\hline & \multicolumn{3}{|c|}{------Egg laying performance (\%)--- } \\
\hline 21 to 26 & $54 \pm 15$ & $46 \pm 17$ & $69 \pm 14$ \\
\hline 27 to 32 & $73 \pm 5^{b}$ & $77 \pm 3^{b}$ & $84 \pm 2^{a}$ \\
\hline 33 to 38 & $70 \pm 3$ & $76 \pm 4$ & $71 \pm 6$ \\
\hline 39 to 44 & $63 \pm 5^{b}$ & $71 \pm 3^{\mathrm{a}}$ & $71 \pm 4^{\mathrm{a}}$ \\
\hline 45 to 49 & $69 \pm 2$ & $68 \pm 7$ & $74 \pm 2$ \\
\hline Means & $66 \pm 10^{b}$ & $68 \pm 14^{\mathrm{ab}}$ & $74 \pm 9^{a}$ \\
\hline
\end{tabular}

Means \pm standard deviation.

LED, light emitting diode.

$a, b$ Means in the same row without a common superscript differ significantly $(p<0.05)$

\section{Egg quality}

The white LED treatment had the highest egg shell breaking strength throughout the whole experiment except for the first 4 weeks (Table 5). The red light treatment showed no significant difference with the blue light in most of the testing period. However, the red light treatment ducks laid eggs with significantly higher egg shell breaking strength compared to the blue light throughout the whole experiment $(5.25 \pm 0.45$ vs $5.08 \pm 0.49 \mathrm{~kg} / \mathrm{cm}^{2}$ ). There were some significant differences between treatments during the 21 to 25 (blue vs white) and 33 to 37 (white vs red) weeks of age. There was no significant difference in egg shell thickness and egg Haugh unit between treatments throughout the whole experiment (Tables 6, 7).

Table 4. The feed intake of Brown Tsaiya ducks in different treatment groups

\begin{tabular}{|c|c|c|c|}
\hline Weeks of age & White LED & Blue LED & Red LED \\
\hline & \multicolumn{3}{|c|}{ - Feed intake (g/d/bird) - } \\
\hline 21 to 25 & $145 \pm 17^{\mathrm{ab}}$ & $140 \pm 18^{b}$ & $157 \pm 15^{\mathrm{a}}$ \\
\hline 27 to 31 & $140 \pm 7^{b}$ & $145 \pm 8^{\mathrm{ab}}$ & $151 \pm 6^{a}$ \\
\hline 33 to 37 & $142 \pm 12$ & $151 \pm 8$ & $143 \pm 13$ \\
\hline 39 to 43 & $145 \pm 14$ & $152 \pm 8$ & $153 \pm 7$ \\
\hline 45 to 49 & $155 \pm 15^{\mathrm{ab}}$ & $151 \pm 12^{b}$ & $162 \pm 8^{a}$ \\
\hline Means & $145 \pm 14^{b}$ & $148 \pm 12^{\mathrm{ab}}$ & $153 \pm 12^{\mathrm{a}}$ \\
\hline
\end{tabular}

Means \pm standard deviation

LED, light emitting diode.

$a, b$ Means in the same row without a common superscript differ significantly $(p<0.05)$.

Table 5. The egg shell breaking strength of Brown Tsaiya ducks in different treatment groups

\begin{tabular}{lccc}
\hline Weeks of age & White LED & Blue LED & Red LED \\
\hline & ------ Egg shell breaking strength & $\left(\mathrm{kg} / \mathrm{cm}^{2}\right)------$ \\
21 to 25 & $5.29 \pm 0.54$ & $5.05 \pm 0.63$ & $5.33 \pm 0.51$ \\
27 to 31 & $5.59 \pm 0.45^{\mathrm{a}}$ & $5.34 \pm 0.40^{\mathrm{b}}$ & $5.47 \pm 0.40^{\mathrm{ab}}$ \\
33 to 37 & $5.46 \pm 0.38^{\mathrm{a}}$ & $5.20 \pm 0.33^{\mathrm{b}}$ & $5.37 \pm 0.44^{\mathrm{ab}}$ \\
39 to 43 & $5.35 \pm 0.45^{\mathrm{a}}$ & $5.04 \pm 0.45^{\mathrm{b}}$ & $5.06 \pm 0.28^{\mathrm{b}}$ \\
45 to 49 & $5.06 \pm 0.54^{\mathrm{a}}$ & $4.76 \pm 0.42^{\mathrm{b}}$ & $5.03 \pm 0.40^{\mathrm{a}}$ \\
Means & $5.35 \pm 0.50^{\mathrm{a}}$ & $5.08 \pm 0.49^{\mathrm{b}}$ & $5.25 \pm 0.45^{\mathrm{a}}$ \\
\hline
\end{tabular}

Means \pm standard deviation.

LED, light emitting diode.

$a, b$ Means in the same row without a common superscript differ significantly $(p<0.05)$. 
Table 6. The egg shell thickness of Brown Tsaiya ducks in different treatment groups

\begin{tabular}{|c|c|c|c|}
\hline Weeks of age & White LED & Blue LED & Red LED \\
\hline & \multicolumn{3}{|c|}{-Egg shell thickness (mm) } \\
\hline 21 to 25 & $0.399 \pm 0.016^{b}$ & $0.406 \pm 0.010^{\mathrm{a}}$ & $0.401 \pm 0.013^{\mathrm{ab}}$ \\
\hline 27 to & $0.400 \pm 0.009$ & $0.395 \pm 0.010$ & 0.010 \\
\hline 33 to & $0.398 \pm 0.009^{a}$ & $0.397 \pm 0.011^{\mathrm{ab}}$ & $0.392 \pm 0.009^{b}$ \\
\hline 39 to & .014 & & 0.011 \\
\hline 45 to 49 & 0.014 & & $0.383 \pm 0.015$ \\
\hline Means & $0.396 \pm 0.014$ & $0.396 \pm 0.014$ & $0.394 \pm 0.013$ \\
\hline
\end{tabular}

Means \pm standard deviation.

LED, light emitting diode

$a, b$ Means in the same row without a common superscript differ significantly $(p<0.05)$

Table 7. The egg Haugh unit of Brown Tsaiya ducks in different treatment groups

\begin{tabular}{lccc}
\hline Weeks of age & White LED & Blue LED & Red LED \\
\hline & - & - & Haugh unit \\
21 to 25 & $88 \pm 7$ & $90 \pm 7$ & $90 \pm 6$ \\
27 to 31 & $87 \pm 6^{\text {ab }}$ & $88 \pm 8^{\mathrm{a}}$ & $86 \pm 8^{\mathrm{b}}$ \\
33 to 37 & $84 \pm 7$ & $85 \pm 9$ & $86 \pm 8$ \\
39 to 43 & $86 \pm 9^{\mathrm{ab}}$ & $84 \pm 9^{\mathrm{b}}$ & $88 \pm 9^{\mathrm{a}}$ \\
45 to 49 & $88 \pm 8$ & $87 \pm 8$ & $86 \pm 9$ \\
Means & $87 \pm 8$ & $87 \pm 9$ & $87 \pm 8$ \\
\hline
\end{tabular}

Means \pm standard deviation.

LED, light emitting diode.

a,b Means in the same row without a common superscript differ significantly $(p<0.05)$

The eggs laid by the blue LED treatment had heavier egg weight during the 27 to 49 weeks of age period and therefore caused heavier egg weight $(64.6 \pm 4.4 \mathrm{~g})$ than eggs laid by the white $(63.1 \pm 4.0 \mathrm{~g})$ and red $(62.8 \pm 4.5 \mathrm{~g})$ LED treatments through the whole experiment (Table 8).

Blood hormone levels

Ducks exposed to the red LED illumination showed higher blood estradiol at 22 to $26(421 \pm 168 \mathrm{pg} / \mathrm{mL}), 34$ to $38(442 \pm$ $304 \mathrm{pg} / \mathrm{mL}$ ) weeks of age and therefore, through the whole

Table 8. The egg weight of Brown Tsaiya ducks in different treatment groups

\begin{tabular}{lccc}
\hline Weeks of age & White LED & Blue LED & Red LED \\
\hline & - & \\
21 to 25 & $57.2 \pm 4.1$ & $58.4 \pm 4.3$ & $56.2 \pm 4.3$ \\
27 to 31 & $62.8 \pm 1.3^{\mathrm{ab}}$ & $63.3 \pm 1.5^{\mathrm{a}}$ & $62.1 \pm 1.4^{\mathrm{b}}$ \\
33 to 37 & $64.1 \pm 2.0^{\mathrm{b}}$ & $65.4 \pm 1.8^{\mathrm{a}}$ & $63.3 \pm 2.4^{\mathrm{b}}$ \\
39 to 43 & $65.0 \pm 2.2^{\mathrm{b}}$ & $66.7 \pm 2.0^{\mathrm{a}}$ & $65.4 \pm 1.5^{\mathrm{b}}$ \\
45 to 49 & $66.3 \pm 2.1^{\mathrm{b}}$ & $69.0 \pm 1.8^{\mathrm{a}}$ & $67.1 \pm 1.5^{\mathrm{b}}$ \\
Means & $63.1 \pm 4.0^{\mathrm{b}}$ & $64.6 \pm 4.4^{\mathrm{a}}$ & $62.8 \pm 4.5^{\mathrm{b}}$ \\
\hline
\end{tabular}

Means \pm standard deviation.

LED, light emitting diode.

$a, b$ Means in the same row without a common superscript differ significantly $(p<0.05)$ experiment (red $471 \pm 296 \mathrm{pg} / \mathrm{mL}$ vs white $344 \pm 356 \mathrm{pg} / \mathrm{mL}$ and blue $336 \pm 188 \mathrm{pg} / \mathrm{mL}$ ). However, the blood progesterone concentration results between different treatments did not show any significant difference in this experiment (Table 9).

\section{Behavior observation}

As shown in Table 10, ducks exposed to blue light significantly change their behavior compared to the white $(\mathrm{p}=$ $0.0223)$ and the red illumination $(\mathrm{p}=0.0352)$. There was no significant difference in behavior between white and red treatments.

\section{DISCUSSION}

From the egg laying performance results, we found that the red LED illumination stimulated the duck sexual maturation. The red LED light treatment showed a significantly higher egg laying performance trend from 21 to 26 weeks of age ( $p$ $=0.0664$ ) and determined periods thereafter (Table 3 ). This is consistent with the results of Borille et al [16] who found that white and red LED treatment ducks laid more eggs than blue, yellow and green LED treatments when given 17 hours of illumination. Pyrzak et al [17] also reported that red light stimuli hens produced more eggs than blue light in two laying cycles. Kim et al [18] concluded that pullets under red LED sexually matured earlier than those in all other light treatments including white and blue LED light. Blue LED light also delayed the hens' sexual maturation time compared to

Table 9. The blood hormone levels of Brown Tsaiya ducks in different treatment groups

\begin{tabular}{|c|c|c|c|}
\hline Items & White LED & Blue LED & Red LED \\
\hline & \multicolumn{3}{|c|}{22 to 26 wk of age - } \\
\hline Estradiol (pg/mL) & $360 \pm 362^{\mathrm{ab}}$ & $280 \pm 126^{b}$ & $421 \pm 168^{a}$ \\
\hline \multirow[t]{2}{*}{ Progesterone (ng/mL) } & $0.43 \pm 0.49$ & $0.44 \pm 0.27$ & $0.50 \pm 0.28$ \\
\hline & \multicolumn{3}{|c|}{-- 28 to 32 wk of age } \\
\hline Estradiol (pg/mL) & $329 \pm 247$ & $358 \pm 237$ & $400 \pm 174$ \\
\hline \multirow[t]{2}{*}{ Progesterone (ng/mL) } & $0.38 \pm 0.25$ & $0.42 \pm 0.33$ & $0.36 \pm 0.16$ \\
\hline & \multicolumn{3}{|c|}{34 to 38 wk of age - } \\
\hline Estradiol (pg/mL) & $315 \pm 157^{b}$ & $379 \pm 212^{\mathrm{ab}}$ & $442 \pm 304^{a}$ \\
\hline \multirow[t]{2}{*}{ Progesterone (ng/mL) } & $0.31 \pm 0.17$ & $0.40 \pm 0.30$ & $0.33 \pm 0.24$ \\
\hline & \multicolumn{3}{|c|}{--- 40 to 44 wk of age --.-- } \\
\hline Estradiol (pg/mL) & $411 \pm 607$ & $352 \pm 202$ & $407 \pm 411$ \\
\hline \multirow[t]{2}{*}{ Progesterone (ng/mL) } & $0.31 \pm 0.22$ & $0.51 \pm 0.55$ & $0.38 \pm 0.56$ \\
\hline & \multicolumn{3}{|c|}{46 to 48 wk of age } \\
\hline Estradiol (pg/mL) & $285 \pm 132$ & $299 \pm 70$ & $415 \pm 379$ \\
\hline Progesterone (ng/mL) & $0.23 \pm 0.16$ & $0.31 \pm 0.18$ & $0.38 \pm 0.41$ \\
\hline Estradiol (pg/mL) & $344 \pm 356^{b}$ & $336 \pm 188^{b}$ & $417 \pm 296^{a}$ \\
\hline Progesterone (ng/mL) & $0.34 \pm 0.30$ & $0.43 \pm 0.36$ & $0.39 \pm 0.35$ \\
\hline
\end{tabular}


Table 10. The results of Brown Tsaiya ducks behavior pattern in different treatment groups (\%)

\begin{tabular}{lccc}
\hline Items & White LED & Blue LED & Red LED \\
\hline Original behavior & & & \\
Feeding & 7.9 & 7.0 & 7.8 \\
Drinking & 11.3 & 10.3 & 12.6 \\
Preening & 30 & 24.5 & 26.6 \\
Frolicking & 9.5 & 12.4 & 10.6 \\
Standing & 26.3 & 33.5 & 25.6 \\
Crouching & 6.3 & 5.1 & 8.0 \\
Sleeping & 3.1 & 1.1 & 3.9 \\
$\quad$ Wagging & 5.8 & 6.1 & 4.9 \\
Main behavior category & & & \\
$\quad$ Feeding & 19.12 & 17.25 & 20.38 \\
$\quad$ Activities & 45.25 & 43.00 & 42.12 \\
Resting & 35.63 & 39.75 & 37.50 \\
Probability of ChiSq & & 0.0162 & \\
Analysis of contrast & & & \\
White vs blue & & 0.0223 & \\
White vs red & & 0.1359 & \\
Blue vs red & & 0.0352 & \\
\hline
\end{tabular}

LED, light emitting diode.

incandescent light (control), white and red light. Our experiment observed that red LED treatment laid more eggs from 21 to 32 weeks of age. Hassan et al [19] tested the effects of different illuminations including red, green, blue, white, combined red, green and red, green, blue. Their results indicated that there were no significant differences between the treatments which contained at least 12 hours of red light. This showed the importance of red light on laying hens reproductive traits.

It is already known that birds had peak sensitivity to yellow and green wavelengths. Nevertheless, some references indicated that birds exposed to green light would delay sexual maturation time, exhibit reduced egg production and GnRH-I mRNA expression $[20,21]$. Furthermore, the green light treatment would inhibit reproduction [20]. In contrast, some researches demonstrated that red lights could accelerate sexual development and maturity in poultry $[20,22]$. The results from some studies showed that monochromatic red light produced higher egg production than those reared under white, green [17,21-23] and blue LED light [24].

Our results for the effects of different color illumination on feed intake (Table 4) were not in agreement with some researches $[11,16,24,25]$. Our results showed that red light treatment had similar feed intake with white light. However, the experiment result by Kim et al [18] indicated that laying hens exposed under red light showed higher feed intake than white and blue light. The feed intake difference in our experiment may partially represent the higher egg production from red LED treatment and hence there were no significant differences between white and blue treatments for the most part in this experiment. The feed intakes between these two groups were similar.

Some references referred that exposure to short wavelength lights (e.g., green and blue color) led to improved egg quality (e.g., egg weight, shell thickness or shell strength) when compared to long wavelength lights (e. g., red color) $[17,19]$. However, the improved egg qualities in these cited studies were associated with the relatively lower egg production of birds as reported in the studies to a certain extent. In contrast, many cited studies reported that no differences between or among lights in sexual maturity or egg production performance of birds [16,20,24-26]. The different lighting sources were also found to have no effect on egg qualities. Broille et al [16] found that the internal egg qualities (albumen height, specific gravity, and Haugh units) of ISA brown hens at 56 to 72 weeks of age were not influenced by the illumination source including incandescent light, blue, yellow, green, red or white LED light. Kamanli et al [26] found that incandescent, fluorescent or LED lights did not influence egg qualities. The recent study from Liu et al [5] also indicated that there were no significant differences between poultry-specific LED light and warm-white fluorescent light. Archer [25] did not illustrate a difference in egg production or quality between red and white LED light bulbs. The egg weight result was consistent with Pyrzak et al [17], who reported that hens exposed to blue light laid eggs heavier than eggs laid by hens exposed to red light. Hassan et al [24] reported that red light and white light had the same level of egg weights but both of them were lighter than eggs laid by blue light treatment. In contrast to Svobodova et al [23] referred that there was no significant difference between blue, green, red and yellow light treatments on ISA brown egg weight. Archer [25] reported that red and white LED illumination did not change the egg weight of white Leghorn hens after 54 weeks of treatment. Our results suggest that red light stimulation made lighter egg weight than blue ones. Instead of the higher egg shell breaking strength, if the lighter duck eggs weights are acceptable in the commercial market, given ducks red light would be a better choice for higher egg laying performance and egg shell breaking strength with no adverse effects on egg shell thickness and Haugh unit (Tables 5 to 8).

Some references indicated that the different wavelength illumination could affect the behavior of animals. For meat type chicken, Sultana et al [28] found that broilers were shown to spend more time sitting or standing under short wavelengths (blue/green) and exhibited more locomotion under longer (red/yellow) wavelengths. Prayitno et al [27] concluded that meat chickens in the red and white light were more active, which was evident in the white-reared birds in greater walking activity and in the red-reared birds in greater floor pecking, wing stretching, and aggression. However, this stimulation pattern is not suitable for egg type chicken. 
Huber-Eicher et al [22] reported that the green light (short wavelength light) stimulated laying hens spent more time foraging and pecking at objects than the red light, in contrast, red light increased laying hens feeding frequency, indicating the different light stimulation effects on different poultry species. In our experiment, ducks exposed under red LED illumination showed more time spent on feeding, partially agreed with it, however, owing to the breed (chicken vs duck) and rearing system (floor vs cage) difference, further study should be done for clarifying the actual color stimulation pattern on caged laying ducks.

The duck's plasma estradiol concentration result (Table 9) was partially in agreement with Baxter et al [21] who compared red, green and white light stimulation on white leghorn laying hens. He found that at 20 weeks of age the Estradiol concentrations of the red treatment were significantly higher than those of white and blue treatments. Hassan et al [24] also found that laying hens 22 weeks of age after 10 weeks of red light exposure showed higher serum estradiol concentration than blue light groups. Higher levels of estradiol during egg laying initiation have been correlated with the activity of small follicles [29]. It may partially explain the higher egg laying performance of the red treatment in our experiment. Although the role of estradiol and progesterone are to develop the reproductive organs and initiate ovulation [30], we could not find any difference between the treatments on plasma progesterone. This may be because the oviposition time of ducks occurs from $10 \mathrm{pm}$ to 4 am and blood sample collection time is about 9 am, 13 to 19 hours before oviposition. Thus, the progesterone concentration was at a relatively low level in the serum [30] and thus made the progesterone result difficult to observe.

\section{CONFLICT OF INTEREST}

We certify that there is no conflict of interest with any financial organization regarding the material discussed in the manuscript.

\section{ACKNOWLEDGMENTS}

This research was financially supported by the Council of Agriculture (104AS-2.4.2-LI-L1).

\section{REFERENCES}

1. Riber AB, Ha VDW, de Jong IC, Steenfeldt S. Review of environmental enrichment for broiler chickens. Poult Sci 2018;97:378-96. https://doi.org/10.3382/ps/pex344

2. Rodrigues I, Syihus B, Bedford NR, Gous R, Choct M. Intermittent lighting improves resilience of broilers during the peak phase of sub-clinical necrotic enteritis infection. Poult
Sci 2018;97:438-46. https://doi.org/10.3382/ps/pex315

3. Yang Y, Pan C, Zhong R, Pan J. The quantitative models for broiler chicken response to monochromatic, combined, and mixed light-emitting diode light: a meta-analysis. Poult Sci 2018;97:1980-89. https://doi.org/10.3382/ps/pey065

4. Manser CE. Effects of lighting on the welfare of domestic poultry: a review. Anim Welf 1996;5:341-60.

5. Liu K, Xin H, Sekhon J, Wang T. Effect of fluorescent vs. Poultry-specific light-emitting diode lights on production performance and egg quality of W-36 laying hens. Poult Sci 2018;97:834-44. https://doi.org/10.3382/ps/pex371

6. Lewis PD, Morris TR. Poultry lighting, the theory and practice. 1st ed. Andover-Hampshire, UK: Northcot; 2006.

7. Parvin R, Mushtaq MMH, Kim MJ, Choi HC. Light emitting diode (LED) as a source of monochromatic light: a novel lighting approach for behaviour, physiology and welfare of poultry. World's Poult Sci J 2014;70:543-56. https://doi.org/ 10.1017/S0043933914000592

8. Prescott NB, Wathes CM. Spectral sensitivity of the domestic fowl (Gallus g. domesticus). Br Poult Sci 1999;40:332-39. https://doi.org/10.1080/00071669987412

9. Lewis PD, Gous RM. Responses of poultry to ultraviolet radiation. World's Poult Sci J 2009;65:499-510. https://doi. org/10.1017/S0043933909000361

10. Liberman J. Light: medicine of the future. How we can use it to heal ourselves now. Rochester, VT, USA: Bear and Company; 1991.

11. Rozenboim I, Ziberman E, Gyaryahu G. New monochromatic light source for laying hens. Poult Sci 1998;77:1695-98. https:// doi.org/10.1093/ps/77.11.1695

12. Lewis PD, Caston L, Leeson S. Green light during rearing does not significantly affect the performance of egg-type pullets in the laying phase. Poult Sci 2007;86:739-43. https:// doi.org/10.1093/ps/86.4.739

13. Tai ME, Hsieh HH. Effect of LED chromatic light sources on hatching of broiler breeder eggs. J Chinese Soc Anim Sci 2008; 37:1-8.

14. Benoit J. The role of the eye and the hypothalamus in the photo stimulation of gonads in the duck. Ann NY Acad Sci 1964;117:204-15. https://doi.org/10.1111/j.1749-6632.1964. tb48175.x

15. Lee SR. The relationship between behavior and performance of laying Brown Tsaiya kept in cage [master's thesis]. TaiChung, Taiwan: Chung Hsing University; 1989.

16. Borille R, Garcia RG, Royer AFB, et al. The use of light-emitting diodes (LED) in commercial layer production. Braz J Poult Sci 2013;15:135-40. https://doi.org/10.1590/S1516635X2013000200009

17. Pyrzak R, Snapir N, Goodman G, Perek M. The effect of light wavelength on the production and quality of eggs of the domestic hen. Theriogenology 1987;28:947-60. https://doi. org/10.1016/0093-691X(87)90045-8 
18. Kim MJ, Hossan MS, Akter N, et al. Effect of monochromatic light on sexual maturity, production performance and egg quality of laying hens. Avian Biol Res 2012;5:69-74. https:// doi.org/10.3184/175815512X13350270679453

19. Hassan MR, Sultana S, Choe HS, Ryu KS. Effect of combinations of monochromatic LED light color on the performance and behavior of laying hens. J Poult Sci 2014;51:321-6. https:// doi.org/10.2141/jpsa.0130105

20. Gongruttananum N. Influence of red light on reproductive performance, eggshell ultrastructure, and eye morphology in Thai-native hens. Poult Sci 2011;90:2855-63. https://doi. org/10.3382/ps.2011-01652

21. Baxter M, Joseph N, Osborne VR, Bédécarrats GY. Red light is necessary to activate the reproductive axis in chickens independently of the retina of the eye. Poult Sci 2014;93:128997. https://doi.org/10.3382/ps.2013-03799

22. Huber-Eicher B, Suter A, Spring-Stähli P. Effects of colored light-emitting diode illumination on behavior and performance of laying hens. Poult Sci 2013;92:869-73. https://doi. org/10.3382/ps.2012-02679

23. Svobodova J, Tümova E, Popelarova E, Chodova D. Effect of light colour on egg production and egg contamination. Czech J Anim Sci 2015;60:550-6. https://doi.org/10.17221/8597CJAS

24. Hassan MR, Sultana S, Choe HS, Ryu KS. Effect of monochromatic and combined light colour on performance, blood parameters, ovarian morphology and reproductive hormones in laying hens. Ital J Anim Sci 2013;12:e56. https://doi.org/10. 4081/ijas.2013.e56

25. Archer GS. How does red light affect layer production, fear, and stress? Poult Sci 2019;98:3-8. https://doi.org/10.3382/ps/ pey302

26. Kamanli S, Durmus I, Demir S, Tarim B. Effect of different light sources on performance and egg quality traits in laying hens. Europ Poult Sci 2015;79:109-15. https://doi.org/10.1399/ eps.2015.109

27. Prayitno DS, Phillips CJ, Omeo H. The effects of color of lighting on the behavior and production of meat chickens. Poult Sci 1997;76:452-7. https://doi.org/10.1093/ps/76.3.452

28. Sultana S, Hassan MR, Choe HS, Ryu KS. The effect of monochromatic and mixed LED light colour on the behaviour and fear responses of broiler chicken. Avian Biol Res 2013; 6:207-14. https://doi.org/10.3184/175815513X1373987977 2128

29. Robinson FE, Etches RJ. Ovarian steroidogenesis during foillicular maturation in the domestic fowl (Gallus Domesticus). Biol Reprod 1986;35:1096-105. https://doi.org/10.1095/bio lreprod35.5.1096

30. Onagbesan OM, Metayer S, Tona K, Williams J, Decuypere E, Bruggeman V. Effects of genotype and feed allowance on plasma luteinizing hormones, follicle-stimulating hormones, progesterone, estradiol levels, follicle differentiation, and egg production rates of broiler breeder hens. Poult Sci 2006; 85:1245-58. https://doi.org/10.1093/ps/85.7.1245 